
Clients of the Friendship Centre in Saskatoon Understand Addictions Recovery

\author{
John G. Hansen \\ Department of Sociology, University of Saskatchewan \\ Nicole Callihoo \\ 2014 MPA Candidate, Johnson Shoyoma Graduate School of Public Policy, University \\ of Saskatchewan
}

aboriginal policy studies Vol. 3, no. 1\&2, 2014, pp. 88-111

This article can be found at:

http://ejournals.library.ualberta.ca/index.php/aps/article/view/21702

ISSN: $1923-3299$

Article DOI: http://dx.doi.org/10.5663/aps.v3i1-2.21702

aboriginal policy studies is an online, peer-reviewed and multidisciplinary journal that publishes original, scholarly, and policy-relevant research on issues relevant to Métis, non-status Indians and urban Aboriginal people in Canada. For more information, please contact us at apsjournal@ualberta.ca or visit our website at www.ualberta.ca/nativestudies/aps/.

UNIVERSITY OF ALBERTA

FACULTY OF NATIVE STUDIES
Aboriginal Affairs and Aboriginal Affairs and
Northern Development Canada

Affaires autochtones et Développement du Nord Canada 


\title{
How the Urban Aboriginal Community Members and Clients of the Friendship Centre in Saskatoon Understand Addictions Recovery
}

\author{
John G. Hansen \\ Department of Sociology, University of Saskatchewan
}

Nicole Callihoo

2014 MPA Candidate, Johnson Shoyoma Graduate School of Public Policy, University of Saskatchewan

\begin{abstract}
Addictions recovery is a significant policy issue concerning governance in Aboriginal communities, Saskatchewan, and Canada at large. Aboriginal Friendship Centres are priority areas for improving access to addictions recovery programs and assistance. This article addresses the following priority areas identified by the Saskatoon Aboriginal Friendship Centre and the urban Aboriginal community of Saskatoon in regards to addictions recovery: impoverishment, food shortages, homelessness, and the problem of growing Aboriginal incarceration rates. This study is qualitative in nature and highlights the factors critical to a developing addictions recovery interpretation through the stories of Aboriginal clients who use the services of the Friendship Centre. The article concludes with recommendations that will assist in the development of policy concerning urban Aboriginal issues.
\end{abstract}

\section{Introduction}

In the battle against addictions, the Aboriginal Friendship Centre may be the organization most needed in identifying and promoting addictions recovery. During the past fifty years, Aboriginal Friendship Centres across western Canada have been battling poverty-related issues through an array of services and program responses. In a society where Aboriginal people frequently experience social exclusion, Friendship Centres provide a place for social inclusion within an urban community, as well as providing referrals to essential services, such as employment and housing. In Saskatchewan, the existence of Friendship Centres go back to " 1958 when one of the first Centres opened its doors to respond to the needs Aboriginal people faced as they moved into larger centres. The centres were started and run by community, often based on small donations, volunteers and some grant from governments" (CFNMP 2004, 2: 7-1). In short, Friendship Centres hope to address the needs of urban Aboriginal people by offering the following programs and services:

sports/culture recreation, Aboriginal literacy, music, dance, teen parenting skills, family violence, housing, drugs/alcohol abuse, substance abuse, literacy, job skills, food bank, diabetes education and care, cultural education, court workers, alternative 
measures, Elders, soup lines, fine options, Santa's Anonymous and Christmas gift giving; food at Christmas, Thanksgiving Easter and so on; traditional feasts and ceremonies, meeting and gathering places; Safety shelters (CFNMP 2004, 2: 7-1).

This passage gives an indication of how Aboriginal Friendship Centres address the social, economic, emotional, and spiritual needs of urban Aboriginal people. However, the promising results Friendship Centres are generating for Aboriginal addictions recovery are the focus of the research discussed here. In this article, we will outline relevant literature on addictions recovery in relation to the Aboriginal experience in Canada. Next, we will discuss our research methodology and the results of the data we have collected to determine how the part of the urban Aboriginal community utilizing the Friendship Centre in Saskatoon understands addictions recovery. Third, we acknowledge the limitations of the study. Finally, we will draw conclusions and make recommendations to inform policymaking in respect to urban Aboriginal peoples and addictions recovery. In doing so, we offer Aboriginal perspectives to the body of knowledge.

\section{Review of Relevant Literature}

Recovering from addictions is a challenging undertaking. Various studies have shown that many of the addictions treatment programmes available are not very effective, not very successful, and not very productive at creating or maintaining addictions recovery. For example, some four decades ago, Brecher noted that, after undergoing treatment for addictions, "almost all [addicts] become readdicted and reimprisoned ... [and that] ... for most the process is repeated over and over again" $(1972,71)$. Added to the fact that treatment programs have limited success, is information showing a correlation between addictions and incarceration. This point is important because a common experience for many participants in this study was that they have been incarcerated at some point in their lives. In 2012, Statistics Canada reported that Aboriginals are overrepresented in society's prisons and jails: "In 2010/2011, 27 percent of adults in provincial and territorial custody and 20 percent of those in federal custody involved Aboriginal people, about seven to eight times higher than the proportion of Aboriginal people $(3 \%)$ in the adult population as a whole" (cited in Dauvergne 2012, 11). These kinds of numbers truly demonstrate how the criminal justice system deals with Aboriginal offenders. The Commission on First Nations and Métis People (CFNMP 2004, 9-38) notes that "Aboriginal accused are more likely to be charged with multiple offences ... more than twice as likely to be denied bail ... Aboriginal people often plead guilty because they feel intimidated by court proceedings and want them over with." Today, Aboriginal overrepresentation in custody is so extensive, and Aboriginal underrepresentation as employees in the criminal justice system is so deeply entrenched, that it seriously marginalizes Aboriginal people communities in Canada.

\section{The Role of the Prison Industrial Complex}

As Aboriginal incarceration rates have risen, some scholars have come to believe, in some form, in the theory of the prison industrial complex. The ethnic studies scholar Julia 
Sudbury (2002), in her analysis of the prison industrial complex, draws a parallel between incarcerating Aboriginal peoples, racial minorities, and women, and the expansionism of prisons. According to Sudbury, the prison industrial complex is "made up of an intricate web of relations between state penal institutions, politicians, and profit-driven prison corporations" (57). In other words, the criminal justice system is systematically incarcerating racial minorities, Aboriginals, and women in the name of justice. Corporate elites are accumulating profit and wealth through incarceration, and increasing social inequality through the prison industrial complex. Sudbury claims that "[since] the prison industrial complex (PIC) emerged in the US, the past fifteen years have witnessed its transformation into a global phenomenon" (62). She observes:

Increasingly, black women and women of colour are the raw material that fuel the prison industrial complex: as scapegoats of tough-on-crime rhetoric, targets of drug busting operations that generate millions for police, customs and military budgets, or workers sewing and assembling electronics in prison workshops. There is a need for a new anti-racist feminism that will explore how the complex matrix of race, class, gender, and nationality meshes with contemporary globalized geo-political and economic realities (72).

That Aboriginal men and women are incarcerated in larger numbers in comparison to mainstream Canadians is disturbing. However, we also know from recognized studies that Aboriginal women's oppression is entrenched even more deeply than men's. "The rates of incarceration are even more dramatic for Aboriginal women. Ten years ago it was estimated that in Saskatchewan a treaty Indian woman was 131 times more likely to be incarcerated than a non-Aboriginal woman, while Metis women were twenty-eight times more likely to be incarcerated," wrote prominent critical race scholar Sherene Razack $(2002,134)$. Razack maintains that there are "legal practices in the making and maintaining of a white settler society" (1). In a prison industrial complex system, Aboriginals are overrepresented in custody and the criminal justice system is staffed primarily by a white workforce.

The prison industrial complex can be interpreted a form of ongoing colonial social and political power over Aboriginals, based on the assumption that prison is an effective response to crime and addictions. The prison industrial complex seemingly ignores high recidivism rates while embracing colonial notions and practices, such as increasing Indigenous incarceration rates. Because Aboriginal people are the colonized, the prison industrial complex exploits them further in what becomes a colonial distortion of justice. Patricia Monture, a prominent Aboriginal law scholar, claims that Canada is actively engaged in ongoing colonial activities such as incarcerating Aboriginal offenders for profit. She writes:

Aboriginal offenders are the commodities on which Canada's justice system relies. If all Aboriginal offenders were released from custody tomorrow, prisons would be empty and forced to close. Justice personnel from parole officers to correctional workers to police officers would be laid off. The grave majority of any such fantasized 
layoffs would not affect employment in the Aboriginal community. As dramatic as the figures of over-representation of Aboriginal people in the criminal justice system as clients, the under-representation of Aboriginal people as employees within any component of the justice system is equally notable $(1995,1)$.

The prison industrial complex plays an important role in sustaining the ongoing colonization of Aboriginal peoples, who are progressively becoming the human commodities that fuel prison expansionism. Political discourse and "tough on crime" rhetoric together are driving Aboriginals into prisons in increasing rates. The Commission on First Nations and Métis People [CFNMP] Commission has shown that "Canada is a world leader in incarcerating 118 per 100,000 general population" (CFMNP 2004, 9-41). However, the CFNMP has also shown that documented "empirical evidence in the U.S., Canada, and Europe over the last thirty years shows longer sentences do not reduce recidivism" and "longer sentences may increase recidivism" (9-41).

However, we would have to see that those suffering from chemical addictions need more help and healing than they do punishment. The current work of academics and researchers is demonstrating that the most basic need had by many offenders is the need to recover from addictions. For example, Dauvergne documents that "adults who entered custody in 2010/2011 typically had four of the six rehabilitative needs. The most common need was in the area of substance abuse, scored by 9 in 10 adults (92\%) admitted to custody" $(2012,12)$. Given the relationship between addictions and incarceration, we recognize that reducing Aboriginal addictions is extremely important in sustaining a healthy and flourishing Canadian society for a few different reasons. First, Aboriginal peoples are the fastest growing population in the Prairie provinces, and will play a key role in countless societal developments in Canada's future. Aboriginal peoples and communities need to be healthy in order to make positive contributions to Aboriginal society and society at large. However, in order to do this, we should observe the structures and processes that promote community development.

Community promotion means problem solving and identifying community strengths and weaknesses. The focus is on successes. It includes traditional First Nations and Metis justice by stressing First Nations and Metis values and customs. It builds relationships between community and the criminal justice system ... As the delivery of government services shifts to communities, so too must the resources needed to carry out the responsibilities. This does not always occur. "Offloading" is the term used to describe transfer of responsibility without transfer of resources (CFNMP 2004, 1: 2-4).

This passage illustrates the need Aboriginal communities have to receive adequate funding, and that offloading the transfer of responsibility without a transfer of resources is a reflection of ongoing colonial and economic dominance of Aboriginal communities. In other words, settler state policies marginalize Aboriginal communities, and are continuously reproduced to sustain a system of dominance and colonization that remains 
to the present day. Aboriginal community development, for example, requires much more than offloading responsibility without adequate resources.

Perhaps one of the most crucial findings about the participants' experiences was that many were raised in alcoholic homes, and many suffered from some form of childhood abuse. Issues like this concerning the urban Aboriginal community cannot be understood without understanding historical European colonization and its ideology. The residential schools, set up by the Canadian government and run by church missionaries, were instrumental in shaping the current Aboriginal state of loss, alcoholism, lack of parenting skills, and family breakdown. As a rule, the residential schools sought to break down family units and to wipe out Aboriginal languages and culture; in doing so, they abused generations of children emotionally, physically, spiritually, and mentally (Jaine 1993; Aboriginal Justice Inquiry 1999; CFMNP 2004). The eleven participants in this study were either direct survivors of residential schools or were the descendants of residential school survivors. Fortunately, a number of studies have demonstrated that allowing Aboriginal communities to develop their own healing programmes is a positive step towards healing themselves (Aboriginal Justice Inquiry 1999; CFNMP 2004; Green 1998; Ross 1996; Hansen, Booker, and Charlton 2014).

Urban Aboriginal communities utilize and value the community-based programs at Friendship Centres. The research project discussed in this article, initiated by John Hansen of the sociology department at the University of Saskatchewan, is "community-driven" in the sense that the project idea stemmed from the interests and values expressed by employees at the urban Aboriginal Friendship Centres of Saskatchewan, who have spent years working with clients to help them with a wide range of needs. The urban community partners in the study requested Nicole Callihoo, an Aboriginal graduate student at the University of Saskatchewan with extensive experience working with the Friendship Centre Movement, be involved in the study, demonstrating that the community had a say in its development. Appropriately, it was Nicole who interviewed the participants and transcribed the collected data. In doing so, she observed the details and the context of what participants said.

\section{Methodology}

This section discusses the research methodology in this study, which utilized qualitative methods and, more specifically, open-ended interviewing, case study, and narrative. The participants were Aboriginal clients who utilize the Friendship Centre in Saskatoon, and they were interviewed to understand "how" the urban Aboriginal community understands addictions recovery; Creswell advises that qualitative research is suitable when the major research question asks "how" $(1998,17)$. To elaborate, participants were asked the following open-ended interview questions:

- What are the most important factors that lead to addictions recovery from the perspective of Aboriginal people who utilize the Friendship Centre?

- What do Aboriginal clients who utilize the Friendship Centre identify as factors that lead to addictions recovery? 
- What do Aboriginal people who utilize the Friendship Centre perceive as barriers to healing from addictions?

- What do Aboriginals clients who utilize the Friendship Centre perceive that needs to be done to promote addictions recovery?

These kinds of questions suggest this inquiry is suitable for a qualitative examination. Creswell $(1998,15)$ advises a qualitative inquiry entail that "the researcher builds a complex, holistic picture, analyzes words, reports detailed views of informants, and conducts the study in a natural setting." The traditions that are utilized in this research include narrative, ethnography, and case study. For Creswell, qualitative research offers:

i) a systematic procedure for inquiry;

ii) access to natural cultural settings;

iii) collection of a variety of empirical resources, including:

Case study

Personal experience

Interviews

Introspection

Observation in cultural context

Historical, International and Visual texts $(1998,15)$

The methods of case study, personal experience, interviews, and introspection have been put into practice with this study. The participants were recruited through postings at various community-based agencies. The posting sought First Nations, Métis, or Inuit people residing in Saskatoon who had experienced or were currently experiencing addictions issues. As this research is related to Friendship Centres, each participant also had to have knowledge of Friendship Centres, and either be current or past clients or have participated in the programming at Friendship Centres in general. Nicole Callihoo conducted in-depth interviews with eleven participants who identified themselves as Aboriginal. It is important to note that this study uses the term "Aboriginal" to refer to First Nations, Inuit, and Métis people in Canada. In hindsight, a limitation of this study is that we did not ask participants to specify if they were Status Indians as defined by the Indian Act of 1876, Non-Status, Métis, or Inuit. Such factors lead to diverse experiences in an urban setting. For example, Status Indians are eligible to receive funding for post-secondary educational opportunities for which Non-Status Indians are not eligible.

The qualitative research questions that were posed to Friendship Centre clients explored the lived experience of those clients in the following ways: 
- What factors lead to addictions recovery?

- What factors lead to relapse?

- What barriers are there to healing from addictions?

- Which actions, programs, or assistance needed in the community to promote addictions recovery do they have?

\section{Explaining Addictions Recovery}

Addictions recovery is a complex process made up of a conscious choice to be sober and/or clean, an active support system, and a sense of belonging to a community. Sobriety is perhaps the best-known indicator of addictions recovery; however, we would have to say that harm reduction is also an important step in moving towards addictions recovery. For example, if someone is drinking heavily and then decreases their drinking, it is a step towards recovery; that person is, in other words, exercising harm reduction. According to the International Harm Reduction Association (IHRA), the theory of harm reduction refers to the "policies, programmes and practices that aim primarily to reduce the adverse health, social and economic consequences of the use of legal and illegal psychoactive drugs without necessarily reducing drug consumption" $(2010,1)$. The harm reduction concept holds that the addictions recovery process has other options than abstinence. The IHRA maintains that "small gains for many people have more benefit for a community than heroic gains achieved for a select few. People are much more likely to take multiple tiny steps rather than one or two huge steps" $(2010,2)$. Healing from addictions usually does not occur instantly; instead, many people tend to relapse. Understood this way, harm reduction is a good thing.

Aboriginal people in Canada have a unique history, in that no other group in Canada has been subjected to residential schools in an attempt to destroy their culture and to force assimilation. Today, however, researchers from a variety of disciplines are particularly interested in creating and establishing culturally appropriate programs to provide possible solutions for addictions recovery and healing Aboriginal communities. Chansonneuve, for example, notes that Aboriginal "communities in all parts of Canada have created a revolutionary approach to healing that is grounded in their cultural teachings" $(2007,73)$, and maintains that:

The origins of alcohol abuse can be found in early Canadian history with the introduction of liquor by European fur traders in the early seventeenth century. Prior to this, drunkenness and violence were virtually unknown to Aboriginal people ... As well as introducing alcohol, trading practices had a dramatic impact on traditional diet: healthy, natural foods readily available through hunting, gathering, and agriculture were gradually replaced with convenience foods (7). 
Aboriginal people were much healthier prior to colonialism, as Chansonneuve clearly indicates, and colonialism does not bring progress and benefits to Aboriginal populations, as many colonial historians and thinkers would like us to believe. Instead, colonialism exploits Aboriginal peoples and appropriates their lands and resources (Adams 1999; Charlton and Hansen 2013; Smith 1999). Hansen $(2012,1)$ concurs that a Western statesanctioned "retributive justice system ... has been used to colonize and marginalize Indigenous peoples."

According to Wotherspoon and Hansen, Aboriginal people are also socially excluded in Canadian society: "there is extensive evidence of how discourses of colonialism, racism, and social exclusion have been exhibited by the police, courts, and others in the process of interpreting Indigeneity in accordance with racial constructs" $(2013,30)$. Studies have shown that being socially excluded is an emotionally painful experience and, ultimately, hazardous to health. As Downey and Feldman $(1996,1327)$ assert, " $[t]$ he desire to achieve acceptance and to avoid rejection is widely acknowledged to be a central human motive." Research pertaining to the expectation of prejudice, by Mendoza-Denton et al (2002), concluded that experiences of social exclusion may lead people to expect, nervously, that they will be treated negatively in new situations where the possibility of discrimination exists.

Reactions to exclusion and rejection have been found to include hostility, emotional withdrawal, and depression and jealousy (Downey and Feldman 1996). Medical research has shown, through the use of functional magnetic resonance imaging (fMRI), that social rejection triggers the activation of brain regions comparable to those triggered by physical pain (Eisenberger et al. 2003). Not only is a socially exclusive society creating depressed, angry, disconnected individuals who are mentally and physically hurting, but the harmful effects of social exclusion and rejection continue to echo long after each instance; and they accumulate. (Baldwin 2005) During the course of our research, many participants provided their lived experience of racism and marginalization with stories about issues of justice, poverty, and homelessness. Similarly, Kitchen et al. argue that when human beings lack a sense of belonging to a community, their health deteriorates.

Sense of community belonging is a concept related to levels of social attachment among individuals and is indicative of social engagement and participation within communities. Social isolation can adversely affect health while social engagement and attachment can lead to positive health outcomes and significantly reduce mortality risk $(2012,104)$.

Although Aboriginal people experience social exclusion, racism, and discrimination, there are social advocates who have produced favourable accounts of Aboriginal healing strategies that are culturally appropriate, such as Aboriginal cultural practices, healing circles, sharing circles, and traditional teachings. Aboriginal healing strategies must emphasize culturally appropriate programming in the addictions recovery process (Tempier et al. 2011; Hansen, Booker, and Charlton 2014). As the majority of participants in our study indicate, cultural teachings are a major factor in the development of addictions recovery. 


\section{Social Exclusion and Racism}

Assumptions about Aboriginal peoples in Canada and many other colonial countries are often marked with negative undertones, and the images of the "drunken Indian" and "Indian Outlaws," which have dominated society for so long, are now recognized as colonial stereotypes. Stereotypes like these have been an important factor in the development of systemic discrimination against Aboriginal peoples (Comack 2012; Hansen 2013). As Friesen acknowledges, "a rapidly urbanizing society has forced Native people to migrate to the cities in search of housing and employment, only to encounter severe discrimination and racism" $(2000,19)$. The implications of being socially excluded are serious; as Marshall notes, "poverty, unemployment, racial inequality, social prejudice, family dysfunction, and drug and alcohol abuse all have a role in fostering crime. A significant proportion of criminal offenders have been offended against as children before they became offenders" $(2006,123)$. Since problematic usage of alcohol and drugs has a role in the production of crime, we see a need to enhance our understanding of how people can heal their addictions. In terms of how colonialism created a cycle of abuse for Aboriginal peoples, we know from documented evidence that the Indian residential schools devastated Aboriginal language, parenting skills, culture, and identity, and that the cycle of alcohol, addictions and violence that arose in many Aboriginal communities as a consequence remains to the present day (Jaine 1993; Aboriginal Justice Inquiry 1999; Commission on First Nations and Métis Peoples 2004; Hansen 2013).

Current works by Aboriginal and non-Aboriginal scholars acknowledge the widespread discrimination faced by Aboriginal peoples, who represent the fastest growing population in the Prairie provinces (Statistics Canada). At the same time, the Aboriginal prison population is expanding and growing. Given the relationship between substance abuse and incarceration, it is important to note the warning from Howard Sapers, Canada's ombudsman for prisoners, that the prison population is increasing. He finds it particularly concerning that, of "the growth, 52 percent has come from the Prairies. It's the fastestgrowing region in the country and aboriginal offenders account for most of the increase and account for 43 percent of the offenders in that region," (CBC National News, 18 Sept. 2012).

What Aboriginal peoples face may seem insurmountable, but we learned something from all the participants and from all the obstacles and setbacks that influence addictions relapse. We learned that recovering addicts are always stronger than they realize. How are addicts able to recover? How exactly do their minds function? We, the writers, are Aboriginal researchers who have experienced life in in the culture of the Aboriginal, so we have had ample time to observe how some of our peers deal with addictions recovery. The approach to life of many of the participants is shaped by social and historical factors beyond their individual control, and the acknowledgement of systemic discrimination, institutional racism, and ongoing colonialism help to explain their marginalization.

However, sociologists have long known that addictions treatment programs are not very effective at healing chemically dependent human beings, as "almost all [addicts] 
become readdicted and reimprisoned ... [and that] ... for most the process is repeated over and over again" (Brecher 1972, 71). Given the problematic history of addictions recovery programs, we see a need to expand our knowledge, understanding, and ways of thinking innovatively about Aboriginal additions recovery. According to Hansen, Booker, and Charlton, recovering addicts often share common experiences in their healing journey:

Fellowship or group-the respondents recognised the importance of having a community, and expressed the notion that people need other people. The community, the Fellowships, a place to live, and a job ...

Alcoholics Anonymous-The respondents described Alcoholic Anonymous approaches to dealing with addictions and one may interpret this in accordance with the notions of having a community ...

Helping others-respondents mentioned that helping others are significant to their healing and sobriety. The respondents expressed that people need each other and that helping others is important to their own wellbeing...

Accepting responsibility-The respondents expressed that making a conscious choice to sober up and accept responsibility for one's past actions were instrumental in contributing to their healing journey of that led to cycle of sobriety that remains to the present time...

Spirituality-The significance of spirituality; A significant finding in this study was that participants expressed that spirituality is paramount to the healing process...

Incarceration-is counterproductive to healing from addictions $(2014,262-63)$.

In fact, a common theme amongst the participants who utilized the Saskatoon Aboriginal Friendship Centre was that their conscious decisions to battle their addictions and sober up came from the fact that they had children.

In their analysis of addictions recovery, Tempier et al. (2011) make a connection between painful life experience and a recovery from addictions. Those participants whose driving force to recovery came from a return to traditional teachings "emphasize that cultural understanding is foundational to the well-being of Aboriginal peoples" $(2011,14)$. Such findings contribute to the growing Aboriginal discourse that advocates for decolonization of Aboriginal culture, traditional teachings, and philosophical thought.

\section{The Need for Social Inclusion or Community}

A key factor in understanding how addictions recovery works is realizing that chemically dependent people have feelings, with emotional requirements and a need to sense that they are accepted as part of a community. This does not mean that recovering addicts live their lives inside a circle of friends who drink excessively or use other drugs: far from it. However, the negative example of friends who drink and do drugs is not what inspires 
healing from addictions. Rather, recovering addicts focus their attention on sobriety-on staying sober, on people who are sober, and what sober people are thinking and feeling, and how they want to be part of that community. The Aboriginal Friendship centre provides recovering addicts with a sober community that accepts them.

\section{Addictions Recovery Indicators}

The element most commonly cited as being needed in recovering from addiction is children and family. It is the most cited factor in the participants' responses to the question about why they decided to regulate and limit substance use, and the case studies demonstrate how family supports and having children suppresses substance use or abuse. It is significant that chemically addicted individuals need, emotionally, to have a responsibility and duty to their children and family to prevent themselves from abusing substances. This emotional connection to children and family also seems to enhance the ability to recover from addictions. This connection is most probably why there has been incredible interest among scholarly addiction counsellors, and Aboriginal-based justice programs, over patients' needs for family and community supports. Understood this way, we can look at having children and family responsibility as being a crucial factor in the battle against addictions, and see the inspiration for addictions recovery that having children and a family has generated, based on participant narratives.

\section{Themes}

Each of the respondents experienced many different kinds of life-changing events that either led to recovery or relapse. The most often-cited reason for recovery had to do with children and family. Other reasons mentioned as leading to recovery were: being in corrections; health reasons; to have a better life; cultural reasons; the loss or breakup of family. The most cited reason for relapse was the loss or death of family members. Other reasons for relapse were family breakup, correction issues, stress, and addicted friends.

\section{Analysis}

The interviews with the participants provided the data for analysis. All interviews were transcribed by Nicole, and we were able to observe the details and the context of the participant's life experiences and perceptions. The process of transcribing the interviews has assisted in the development of understanding for the topic. Wood and Kroger for example, share this assessment: they argue that transcribing "is both part of and necessary for analysis" $(2000,87)$. While the transcriptions initially included the speech hesitations, the "ehs and uhs," we decided, in the end, to exclude these stammers in the presentation as they do not contribute anything important to the kind of analysis that we are concerned with.

We read and examined the interviews again carefully before we began the cross-case analysis. From that point, we identified broad categories that we developed into themes. The 
following were some of the themes we observed as significant to the addictions recovery topic:

- Aboriginal Friendship Centres are seen as a place for community and have the ability to assist in addictions recovery;

- children and family are factors in decisions by individuals to enter recovery and begin a sober lifestyle;

- spirituality and ceremonies are seen as important factors in individual recovery process;

- traditional Healing circles should be offered at Friendship Centres as an effort to increase recovery and healing in our community;

- connection to a community is an important factor in going to a Friendship Centre;

- access to cultural programs and counselling are gaps in programming at the Friendship Centre in Saskatoon;

- meals and food programs are seen as an important program to the community;

- Alcoholics Anonymous meetings do assist in the recovery process.

The data analysis was developed by examining the interviews, which were then reviewed to identify themes that corresponded to addictions recovery. As this process developed, the theme emerged that social inclusion at the Aboriginal Friendship Centre was important for participants. Creswell (1998) has suggested that, when several case studies are used, a description of each case, termed "within-case analysis," should be put forth. After our within-case analysis was finished, we carried out a cross-case analysis to manage emerging themes in the data. This qualitative research produced what Denzin calls a "rich, thick description" $(1989,83)$ from each participant, and themes, as Creswell $(1998,63)$ suggested, were identified. Identified themes were organized around healing mechanisms identified by participants, such as: traditional teachings, the sense of belonging to a community, spirituality, and ceremonies. Data also produced thematic contributing factors to addictions, such as the death or loss of family members, stress, addicted friends, incarceration, residential schools, history of addictions with family members, childhood trauma, and so on, as identified by the participants. The analysis of the data became feasible by carefully discussing the information garnered from the interviews, the field notes, and the transcripts with the participants.

For the most part, the participants expressed the feeling that addictions recovery is a community responsibility that takes a holistic approach to conflict resolution. It is holistic in terms of its emotional, physical, mental, and spiritual approach. For the most part, participants described addictions recovery as being based in a model of healing, rather 
than punishment, and identified healing factors as practices that promoted healing in the urban Aboriginal community at large. The thematic addictions recovery factors identified by the participants are having children and family, counselling, traditional teachings, sweat lodge ceremonies, spirituality, and community inclusion. Participants expressed that the Aboriginal Friendship Centre was beneficial to them socially, culturally, and personally.

However, in addition to identifying addictions recovery factors, participants also identified factors that lead them to relapses. The thematic factors that led them to relapse were: stresses, specifically the death of a loved one; incarcerations; a breakup with a spouse; and associating with chemically addicted friends. Since they were Indian residential school survivors and their descendants, participants exhibited residual effects of residential schooling, such as the loss of traditional teachings, ceremonies, and a language, as the schools attempted to assimilate them while erasing their culture. The participant interviews have provided us with a summary of healing factors as well as healing obstruction factors, out of which an addictions recovery ideology emerged. As the participants identified the important role in providing social support played by Aboriginal Friendship Centres, we see how addictions recovery ideas and practices have become enmeshed with cultural teachings and community inclusion.

\section{Important Factors in Participants' Lives}

The participants helped to identify major factors that led to their healing from addictions, such as the responsibilities associated with having children and a sense of family support. Relapsing back into addictions was very much related to loss and the stress of experiencing the death of a family member or loved one. Another commonly held experience among the participants was that they, or someone in their family, had attended an Indian residential school. The colonial spirit of Indian residential schools, and their systematic suppression of traditional culture, values, teaching, and language, resulting in generations of social problems in the Aboriginal world, has been well-documented. Their effects include social problems such as low self-esteem, alcoholism, incarceration, and the erosion and loss of language, parenting skills, and other cultural skills (Hansen 2013; Jaine 1993; RCAP 1996; Cuthand 2005; CFNMP 2004).

The following is an excerpt from an interview with a participant, describing the impact of residential schools on his family:

"Yeah, my dad did, I think my mom did too (attended residential school), my natural mom. I can see how the residential school, how it affected my granny, eh, and then how she raised her kids, then how we were raised" (quote from C-11).

The effects of residential schools are intergenerational, and a factor in this addicted participant's family history, and the histories of many of the other participants. Their alienation from cultural teachings and values decreases their abilities to heal emotionally. The residential schools, as well as imperialist public education, played an important role in the suppression of traditional teachings, language, and culture, which participants suggest is the cause of various social problems in their home communities. 
The relationship between residential schools and social dysfunction is well recorded (Jaine 1993; RCAP 1996; Cuthand 2005). It is also commonly understood that those who have been abused tend to become abusers. As the Commission on First Nations and Métis People observed, "Those who commit crimes often had a childhood in which they were exposed to drug and alcohol use, physical and sexual abuse and poverty" (CFNMP 2004, $2-5)$. One can argue that the abuses that occurred in the residential schools provided a significant stimulus in creating a vicious cycle of social dysfunction and disarray that remains to the present time.

\section{Looking at the Data}

For the most part, the participants expressed that addictions recovery is a significant challenge and that having a sense of family and community is significant to the recovery process. Through their experience, Aboriginal Friendship Centre supports families and provides a sense of recovery. Healing factors are the practices identified by participants that promote healing from addictions. The thematic healing factors most mentioned by the participants are: having children; family support; counselling; a sense of belonging to a community, such as an Aboriginal Friendship Centre; traditional teachings; sweat lodge ceremonies; spirituality; and Alcoholics Anonymous. In the following interview excerpt, the participant is describing the programs and services offered at the Friendship Centre that he found useful to his recovery:

"I like the dances and the cultural gatherings, you know, the round dances and the little gatherings they have there every now, and then that I like and the culture is awesome, you know, it makes people proud when you hear that drum, get that feeling in your chest, yeah, instilling the pride, that's what's gotta happen, it's gonna happen" (quote from C-11).

In contrast, participants identified the factors of relapse or obstructions to recovery as being the death of family member or loss of a close friend, incarceration (jails), the residual effects of the residential schools, friends that drink, and stress.

The following are excerpts from two separate interviews with participants where they are describing their relapse triggers with their addiction:

"Me, yeah, I didn't, I just kept going and, plus with my mother dying and that really pushed me over the edge, I just gave up on everything after that I guess, I don't know, some people grieve some way and some people grieve the other way. Me, my grief is in the bottle" (quote from C-14).

"Yeah, many things (made me relapse), broke up with my girlfriend and I moved away from her and my daughter, and that made me relapse. What else, I have had seventeen friends die of methadone, morphine, and heroin overdoses, and that would make me relapse too" (quote from C-13). 
TABLE 1: Participants

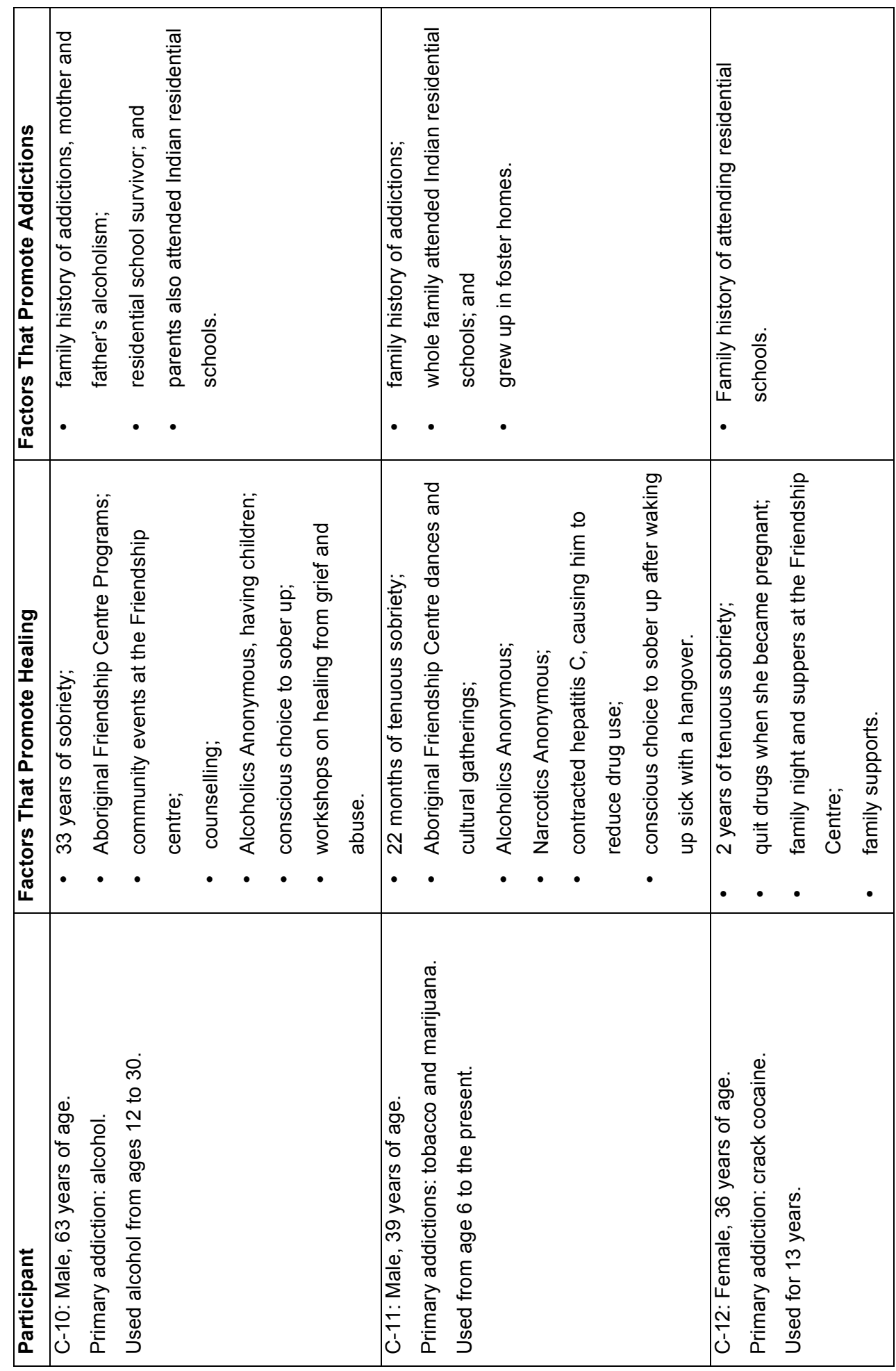




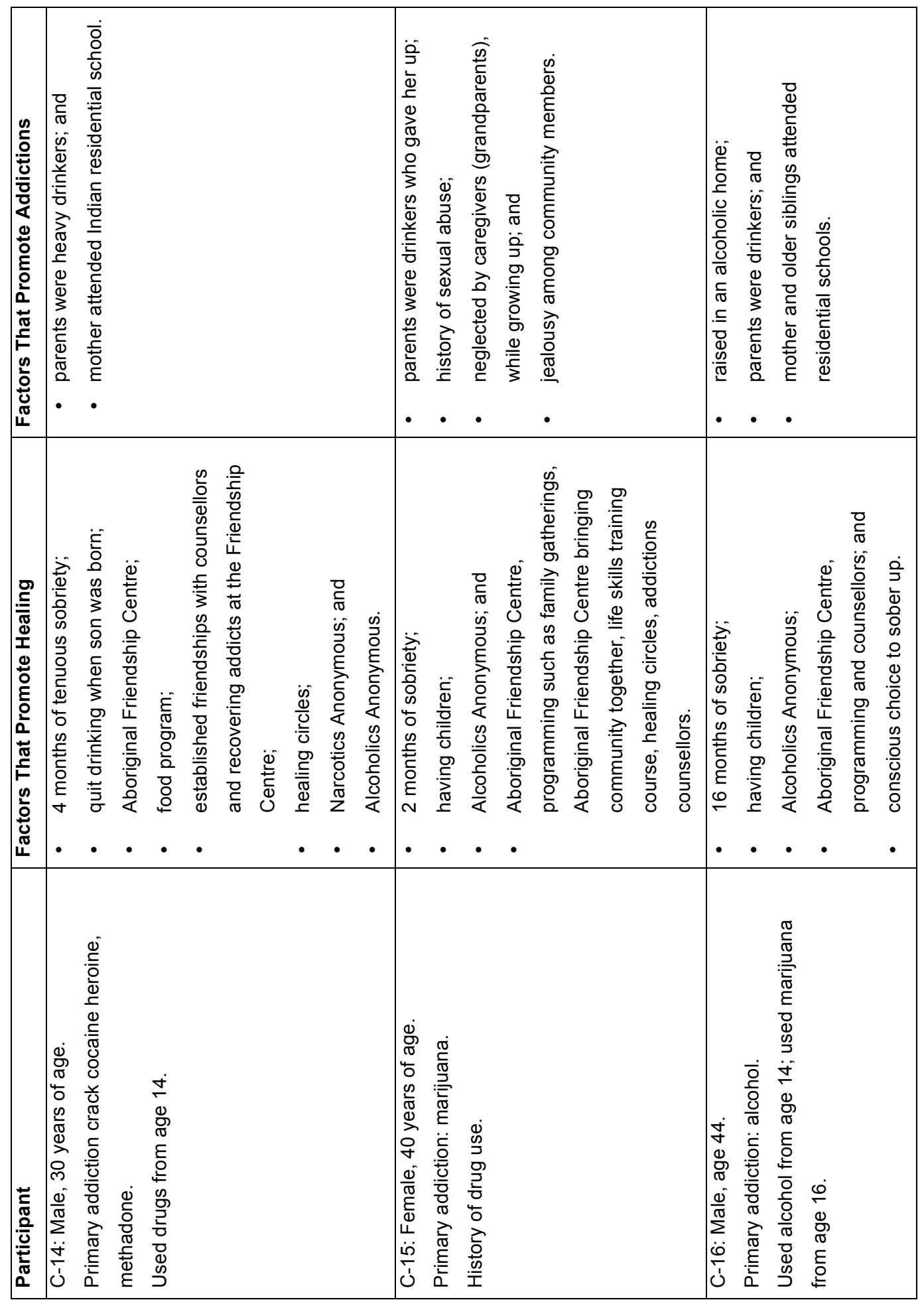




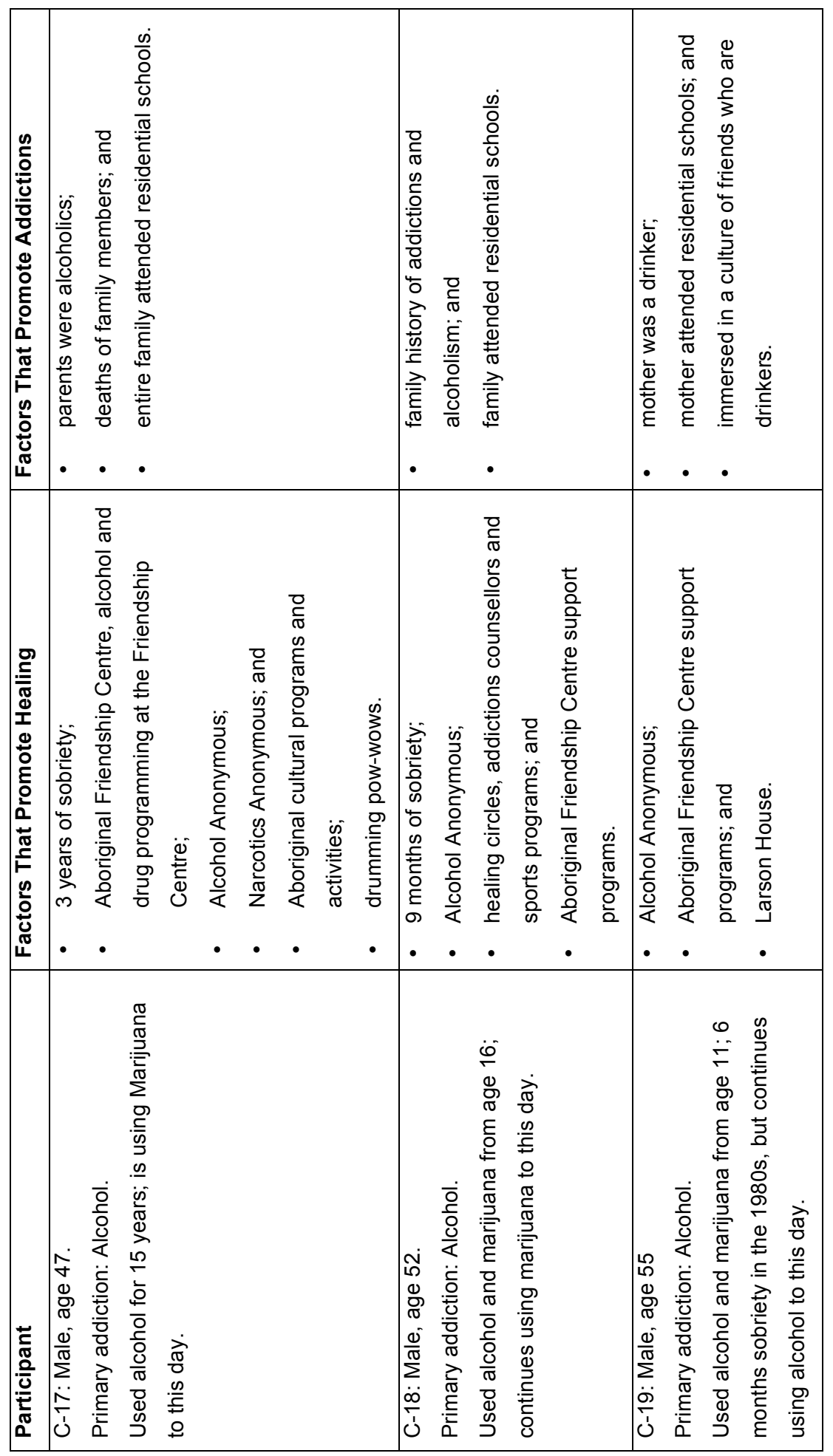




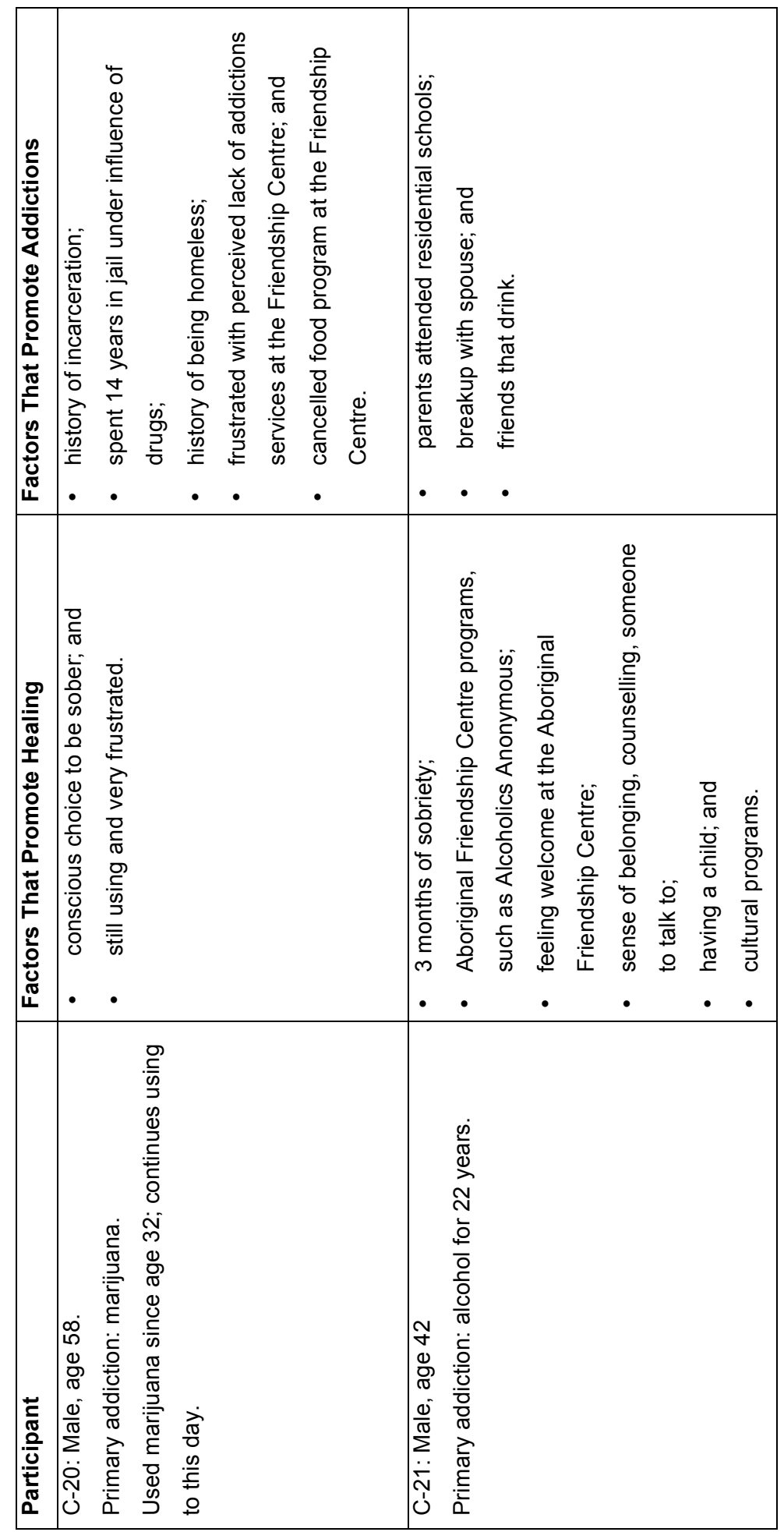


Participants emphasised the importance of the Aboriginal Friendship Centre, illustrating the need for Friendship Centres by the Aboriginal community. The addictions recovery aspects included dissociating with friends that engage in drinking and drug use. The phenomena of having children in the participants' accounts allowed for personal reflection (introspection), which enabled a conscious choice to be sober and for addictions recovery healing to occur. The responsibilities of traditional ways of parenting become enmeshed within family and community. In the participants' interviews, everything was interconnected with community and had a strong spiritual component, which, taken together, serves to make healing from addictions a restorative justice or a holistic matter.

The following is an excerpt from an interview with a participant; at this point in the interview, the participant is describing how the Saskatoon Friendship Centre assists in her recovery:

"Having the counsellors available being able to talk with the resource people there and the unity like, coming together of our people, I found that there is a lot of separation and jealousy among our community members where they ... everybody used to visit with one another and everybody used to support one another, we all worked together, and now it seems that everybody is just on their own or out for themselves and the whole Friendship Centre brings that together, where it's like bringing the people together again" (quote from C-15).

\section{Examining the Participants' Narratives}

Each participant identified factors that inspire healing, as well as factors that inspire addictions in their narratives.

\section{Identifying the Themes}

In Table 2, the healing factors and healing obstruction factors identified by participants are organized into themes.

TABLE 2: Themes

\begin{tabular}{|c|c|}
\hline Factors that promote healing & Factors that obstruct healing \\
\hline $\begin{array}{l}\text { - } \text { Aboriginal Friendship Centre } \\
\text { - } \quad \text { belonging to a community } \\
\text { - } \quad \text { Alcoholics Anonymous }\end{array}$ & $\begin{array}{l}\text { - } \text { family history of addictions } \\
\text { - } \quad \text { parental alcoholism } \\
\text { - } \quad \text { family history of attending residential schools }\end{array}$ \\
\hline
\end{tabular}




\section{Themes}

The thematic healing factors identified by the participants were reconciliation of relationships, a sense of belonging to a community, and Alcoholics Anonymous. Although Alcoholics Anonymous does not come from traditional Aboriginal culture, the participants acknowledge it as helpful to their recovery; perhaps it offers a space where they can feel a sense of community and belonging that make it valuable to them. The thematic healing obstruction factors listed in the table above were family history of addictions, alcoholism, and a history of attending residential schools. Each participant expressed the belief that healing is connected to the community. Healing from addictions apparently involves the reconciliation of relationships that were severed through chemically dependent living. The significant healing obstructions arose from the emotional trauma of family history of dysfunction and alcoholism.

The intergenerational effects of residential schooling, and their contribution to addiction, were expressed by many participants who had either attended residential schools or were descendants of school survivors. Their inability to develop healthy and lasting relationships, and their histories of family breakdown, are acknowledged as being directly related to residential schools (Jaine 1993; CFNMP 2004). This emotional dearth is largely related to traumatic early childhood experiences on the parts of the respondents, and help to explain participants' development of addictions.

Other significant thematic obstructions identified in the emotional realm were growing up in homes where drinking was considered normal. Participants' testimonies reveal that being raised in alcoholic homes was a common theme, and they spoke of being raised in alcoholic homes, where drinking seemed like a normal way of living. Thus, alcoholism within the home played an important role in the development of chemical addictions for participants within this study. It helped shape the foundation of developing addictions.

From the data, we can see how Aboriginal Friendship Centres in general manifest themselves in assisting addicts with recovery by providing a community, social and emotional support, and helping people feel connected to one another. Chemically addicted people often develop a physical dependence on a drug to fill an emotional emptiness, which tells us that recovering addicts need to feel that they belong to a community. This qualitative study identified some important factors for addictions recovery, and recognized the role that the Aboriginal Friendship Centre played in addictions recovery. Therefore, as far as this study is concerned, recovery from alcohol and drug addiction is certainly possible. The participants who utilize the Friendship Centre in this study enhance our knowledge of the challenges they encounter.

The participants were asked to identify gaps in services as they pertain to recovery from addictions, and were asked if any programs should be offered at the Friendship Centre. Many of the respondents stated that cultural, spiritual, or traditional programs are necessary, and need to be offered at the Friendship Centre to assist in recovery. Other participants mentioned long-term treatment, addictions counselling, family counselling, and increased access to AA and hostel services. Clearly, Friendship Centres can do more 
to assist in the recovery process of its clients by offering additional cultural services and access to ceremony.

\section{Limitations of the Study}

There are some limitations in this qualitative study that need to be acknowledged and dealt with in future studies. First, this study is qualitative in nature, and does not claim to speak for all Aboriginal people. It is, however, an example of how a group of Aboriginal participants understand addictions recovery in a particular setting. The openended questions that were used to collect the data discovered that, outside the Aboriginal Friendship Centre, recovery is also influenced by an addict's family, peers, and sense of belonging in general. Insights from the qualitative data should be used to plan a more comprehensive study on addictions recovery in the future. Finally, future studies should focus on gender differences and similarities.

\section{Conclusions}

How the urban Aboriginal community utilizing the Friendship Centre in Saskatoon understands addictions recovery is as both a philosophy and a practice in combating chemical dependency. Intrinsic to that understanding is the sense of community and belonging, possessed by a people that is slowly realizing that they can heal from the trauma and abuses they have experienced. Healing from addictions must challenge the social exclusion of Aboriginal people in the societal realm; in order to do so, one should observe the programs and organizations that promote social inclusion. Aboriginal Friendship Centres, for example, are more than a supplier of urban Aboriginal services. They are an aspect of addictions recovery, an organization designed to counter social exclusion, and a way to assist the Aboriginal community to come together and develop a sense of recovery from addictions. Within the context of colonialism, urban Aboriginals are diverse in that they are a mix of Indigenous cultures and peoples existing within an urban state that have a particular understanding of addictions recovery. The power of healing for urban Aboriginals has been, principally, that of common struggles for social inclusion, food, clothing, and shelter, while the Aboriginal Friendship Centre provides the necessities of that struggle.

The Saskatoon Aboriginal Friendship Centre is a utilized and much-needed organization that assists the urban community in many aspects of their daily lives. The addictions recovery aspects include dissociating with those friends that engage in drinking and drug use. The phenomenon of having children has been a major factor in the development participant's conscious choice to be sober, out of which sobriety emerged. This conscious choice towards addictions recovery inspired by having children, increased participants determination to heal from addictions. Another predictor of success is when addicts have something else in their lives to focus on besides addictions, such as having children. The responsibilities of parenting give them something to focus on, which relates with the need for family and community. Belonging to a community helps to inspire additions recovery via, having a community support system and sense of social inclusion, which may help reduce addictions relapse during stressful life changing events. 
This study found that participants indicate spending time with other recovering addicts at the Aboriginal Friendship Centre made addictions recovery more likely. A strong spiritual or cultural component such as sweat lodge ceremonies, which taken together indicates that healing from addictions is enmeshed with culture. However, in order for addicts emotionally to maintain their recovery, having children is not sufficient in itself. There has be a wide range of social, physical, emotional and spiritual activities and the more holistically developed they are-for example, involved in activities like parenting, education and training, volunteering, cultural activities, and being employed-the more likely they are to be self-fulfilled and therefore more likely to succeed in maintaining sobriety.

\section{Recommendations}

1. This study recommends that local, regional, and national governments increase support for urban services utilized by the Aboriginal community. More specifically, Friendship Centres require access to resources to increase their ability to provide these essential services, like cultural and traditional programming.

2. This study recommends establishing an addictions counsellor devoted to urban Aboriginal health issues; the community would benefit from addictions counsellors at friendship centres. Without these supports from government, Friendship Centres are not able to assist the community in healing and recovery.

3. This study recommends that national and provincial governments revise the funding process for addictions interventions in consultation with Aboriginal communities and increase core-funding measures to programs that are proven successful. 


\section{Bibliography}

Aboriginal Justice Inquiry of Manitoba. 1999. Volume 1: The Justice System and Aboriginal People. Winnipeg: Queens Printer.

Baldwin, M.W., ed. 2005. Interpersonal Cognition. New York: The Guilford Press.

Brecher, E.M. 1972. Licit and Illicit Drugs. Boston: Little \& Brown.

CBC National News. 2012. "Record-high Prison Numbers Sparking Violence." Accessed 18 September 2012. http://www.cbc.ca/news/politics/story/2012/08/27/prisonnumbers-crowding.html.

Chansonneuve, D. 2007. Addictive Behaviours among Aboriginal People in Canada. Ottawa, $\mathrm{ON}$ : Aboriginal Healing Foundation.

Charlton, J. E. and J. G. Hansen 2013. "Poona yetum: Shatter Justice Barriers through Forgiving." The Quint: An Interdisciplinary Quarterly from the North 5 (4): 7-20.

Comack, E. 2012. Racialized Policing: Aboriginal People's Encounters with the Police. Halifax: Fernwood Publishing.

Commission on First Nations and Métis People and Justice Reform (CFNMP). 2004. Legacy of Hope: An Agenda for Change. Final Report from the Commission on First Nations and Métis People and Justice Reform. 2 vols. Accessed 17 March 2014. www. justicereformcomm.sk.ca.

Creswell, J.W. 1998. Qualitative Inquiry and Research Design: Choosing among Five Traditions. Thousand Oaks: Sage.

Cuthand, D. 2005. Tapwe: Selected Columns of Doug Cuthand. Penticton, BC: Theytus Books.

Dauvergne, M. 2012. Adult correctional statistics in Canada, 2010/2011. Canadian Centre for Justice Statistics Component of Statistics Accessed 30 July 2013. http://www. statcan.gc.ca/pub/85-002-x/2012001/article/11715-eng.pdf.

Denzen, N.K. 1989. Interpretive Interactionism. Newbury Park: Sage.

Downey, G., and S.I. Feldman. 1996. "Implications of Rejection Sensitivity for Intimate Relationships." Journal of Personality and Social Psychology 70 (6): 1327-43. http:// dx.doi.org/10.1037//0022-3514.70.6.1327.

Eisenberger, N., M. Lieberman, and K. Williams. 2003. "Does Rejection Hurt? An FMRI Study of Social Exclusion.” Science 61: 459-70. http://dx.doi.org/10.1126/ science.1089134.

Foucault, M. 1975. Discipline and Punish. New York: Random House.

Friesen, J. W. 2000. Aboriginal Spirituality \& Biblical Theology: Closer Than You Think. Calgary: Detselig.

Hansen, J.G. 2012. "Countering Imperial Justice: The Implications of a Cree response to Crime." Indigenous Policy Journal: Journal of the Indigenous Studies Network (ISN) 23 (1): 1-16.

- - - 2013. Swampy Cree Justice: Researching the Ways of the People. 2nd ed. Vernon, BC: J. Charlton Publishing. 
Hansen, J.G., T. A. Booker, and J. E. Charlton. 2014. Walking With Indigenous Philosophy: Justice and Addictions Recovery. 2nd ed. Vernon, BC: J. Charlton Publishing.

International Harm Reduction Association (IHRA). 2010. "What Is Harm Reduction? A Position Statement from the International Harm Reduction Association." Accessed 17 March 2014. http://www.ihra.net/files/2010/05/31/IHRA_HRStatement.pdf.

Jackson, M. 1992. "In Search of the Pathways to Justice: Alternative Dispute Resolution in Aboriginal Communities." Special issue of University of British Columbia Law Review, 147: 147-238.

Jaine, L. 1993. Residential Schools: The Stolen Years. Saskatoon: University of Saskatchewan Extension Press.

Marshall, C. 2006. "Prison, Prisoners and the Bible." Restorative Directions Journal (2) 1: 118-31.

Mendoza-Denton, R., G. Downey, V.J. Purdie, and J. Pietrzak. 2002. "Sensitivity to Statusbased Rejection: Implications for African American Students' College Experience." Journal of Personality and Social Psychology 83 (4): 896-918.

Razack, S. 2002. "When Place Becomes Race." In Race, Place and the Law-Unmapping a White Settler Society, ed. S. Razack, 1-21. Toronto: Between the Lines.

Royal Commission on Aboriginal Peoples (RCAP). 1996. Looking Forward, Looking Back. Vol. 1 of Report of the Royal Commission on Aboriginal People. Ottawa: Canada Communications Group Publishing.

Statistics Canada. 2012. Special Tabulation, Based on 2006 Census of Population.

Sudbury, J. 2002. "Celling Black Bodies: Black Women in the Global Prison Industrial Complex." Special issue, Feminist Review 70: 57-74. http://dx.doi.org/10.1057/ palgrave/fr/9400006.

Tempier, A., C.A. Dell, E. Papequash, R. Duncan, and R. Tempier. 2011. "Awakening: 'Spontaneous Recovery' from Substance Abuse among Aboriginal Peoples in Canada." The International Indigenous Policy Journal 2 (1). http://ir.lib.uwo.ca/iipj/ vol2/iss1/7.

Wood, L.A., and R. O. Kroger. 2000. Doing Discourse Analysis: Methods for Studying Action in Talk and Text. Thousand Oaks: Sage.

Wotherspoon, T., and J. G. Hansen. 2013. “The "Idle No More" Movement: Paradoxes of First Nations Inclusion in the Canadian Context." Social Inclusion 1 (1): 21-36. 